\title{
Ketamine as an Anesthetic for Patients with Acute Brain Injury: A Systematic Review
}

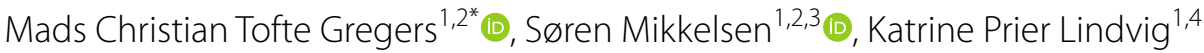 \\ and Anne Craveiro Brøchner $2,4,5$
}

(c) 2020 The Author(s)

\begin{abstract}
For years, the use of ketamine as an anesthetic to patients suffering from acute brain injury has been debated because of its possible deleterious effects on the cerebral circulation and thus on the cerebral perfusion. Early studies suggested that ketamine could increase the intracranial pressure thus lowering the cerebral perfusion and hence reduce the oxygen supply to the injured brain. However, more recent studies are less conclusive and might even indicate that patients with acute brain injury could benefit from ketamine sedation. This systematic review summarizes the evidence regarding the use of ketamine in patients suffering from traumatic brain injury. Databases were searched for studies using ketamine in acute brain injury. Outcomes of interest were mortality, intracranial pressure, cerebral perfusion pressure, blood pressure, heart rate, spreading depolarizations, and neurological function. In total 11 studies were included. The overall level of evidence concerning the use of ketamine in brain injury is low. Only two studies found a small increase in intracranial pressure, while two small studies found decreased levels of intracranial pressure following ketamine administration. We found no evidence of harm during ketamine use in patients suffering from acute brain injury.
\end{abstract}

Keywords: Anesthetics i.v., Ketamine, Traumatic brain injury, Systematic review, Intracranial pressure

\section{Introduction}

Ketamine is the best-known non-competitive $N$-methyl$\mathrm{D}$-aspartate receptor antagonist (NMDA). It was first discovered in 1956, and subsequent animal studies showed promising general anesthetic properties [1]. In 1964, ketamine was introduced as an anesthetic for humans and has thus been available for more than 50 years. Ketamine exists as two optical isomers: $(\mathrm{S})-(+)$ and $(\mathrm{R})-(-)-$ 2-(2-chlorophenyl)-2-(methylamino)cyclohexanone. At present, ketamine is available as S-ketamine, the more potent of the two optical isomers, and as a racemic mixture containing both $(\mathrm{S}+)$ and $(\mathrm{R}-)$ ketamine.

Along with the antagonistic effect on the NMDA receptor shown in in vitro studies, ketamine has been shown

\footnotetext{
*Correspondence: mtoftehansen@gmail.com

${ }^{1}$ The Mobile Emergency Care Unit, Department of Anaesthesiology and Intensive Care, Odense University Hospital, Odense, Denmark Full list of author information is available at the end of the article
}

to interact with opioid, monoaminergic, cholinergic, nikotinergic, and muscarinic receptors assigning ketamine a broad range of effects and side effects [2].

Once bound to the NMDA receptor, ketamine induces a state of dissociation. Contrary to most anesthetic agents, ketamine does not induce dilation of the vascular bed and thus does not induce hypotension, nor does it have a negative chronotropic impact on the heart. This combination makes ketamine a potentially attractive drug when anesthetizing patients with hypotension or patients in whom considerations regarding perfusion pressure during anesthesia are prioritized, as is the case with patients with traumatic brain injury (TBI) $[2,3]$.

Theoretically, ketamine could be beneficial when treating patients with TBI. However, the drug was abandoned in the 1990s due to the suspicion that the drug should have adverse effects on the intracranial pressure [4].

Immediately after the occurrence of a traumatic brain injury numerous changes are initiated in the suffering 
brain. Some of these changes are altered propagation of the complex electrical activity that takes place on the surface of the brain.

Various kinds of electrical propagations have been described; all based on external measurements of the waves by electroencephalography EEG or internal measurements with appropriate electrodes. One type of such electrical propagations is spreading depolarizations (SD) [5-7]. These are waves of abrupt, near-complete breakdown of neuronal transmembrane ion gradients and are phenomena that have been associated with poor neurological outcome in patients with TBI [8]. Spreading depolarizations occur in relation to local ischemia but are also seen in the hours or days after ischemia as the remaining tissue suffers from lack of energy supply.

Recent evaluation of retrospective clinical data and case studies have indicated that there might be a therapeutic effect of ketamine following brain injury as it is assumed that ketamine suppresses SD following brain injury [9].

The aim of this systematic review was to assess the currently available data in humans to determine whether the use of ketamine is beneficial in the treatment of patients with TBI by assessing the literature regarding ketamine and intracranial pressure, cerebral perfusion pressure, and the effects on spreading depolarizations.

\section{Methods}

\section{Protocol and Registration}

We performed the systematic review in accordance with the Preferred Reporting Items for Systematic-Reviews and Meta-Analyses (PRISMA) guidelines [10]. No changes were made to the protocol after initiation of the project. The protocol is unpublished. We used Covidence (an online software) [11], to screen titles, abstracts, and full texts.

\section{Eligibility Criteria}

In this systematic review, only human studies were included. The Population, Intervention, Comparator, Outcome (PICO) model [12] applied was defined as: Among adults and children suffering from severe brain injury on ischemic or traumatic basis in a prehospital setting or in an intensive care setting (population), does use of intravenous ketamine during sedation (intervention), compared to no use of ketamine (comparator), affect the intracranial pressure, cerebral perfusion pressure, spreading depolarizations, mortality, or similar hemodynamically variables [heart rate (HR), systolic blood pressure, mean arterial pressure (MAP)] (outcome). We allowed for papers reporting on combined groups of patients with traumatic injury and patients with anoxic damage caused by non-traumatic injury to be included due to the relative scarcity of data on neurologic injury.
We attempted to identify all relevant randomized clinical trials, prospective trials, and retrospective trials. No studies were excluded because of age of publication. Systematic reviews, abstracts, letters, case reports, or unpublished data were not included, though reference lists of systematic reviews were screened for relevant studies not found in the systematic search. Studies focusing on the effect of ketamine on intracerebral hemodynamics in patients suffering only anoxic damage without TBI, or studies focusing on ketamine administrated during other procedures (e.g., abdominal surgery, heart surgery, known intracranial illness, or similar) were excluded.

\section{Search Strategy}

To identify all trials for inclusion, a detailed systematic search the following electronic registers were used: Cochrane Central Register of Controlled Trials, MEDLINE, PubMed, EMBASE, and Google Scholar. The search was performed in May 2019 using the following MESH terms: Brain injury, ketamin, ketamine, or ketalar. The specific search string used was: (((brain injury) OR brain injuries)) AND (((ketamin) OR ketamine) OR ketalar) NOT (animals $[\mathrm{mh}]$ NOT humans $[\mathrm{mh}])$. A manual search for additional reports in reference lists of identified studies was performed. Further, ClinicalTrials.gov was examined for ongoing unpublished studies.

\section{Study Selection}

Two authors (MCTG and ACB) independently screened all titles and abstracts identified in the search and excluded articles not meeting the inclusion criteria. Two authors (MCTG and ACB) screened all full-text papers selected through the first screening. Any disagreement was resolved by discussion between the two authors and with final decision by a third author (SM and/or KL). If any data or other relevant information were missing, the corresponding authors were contacted. None of the investigators were blinded to the publishing journal, authors, or affiliations. A PRISMA flowchart covering the screening process was made, see Fig. 1.

\section{Validity Assessment}

Two investigators (MCTG and $\mathrm{ACB}$ ) assessed the risk of bias in the included studies. All studies, both randomized, non-randomized, and retrospective studies were evaluated with the standardized Cochrane risk of bias tool at six different domains [13]. Any disagreement was resolved by discussion between the two investigators, and continued disagreements were settled in cooperation with a third investigator (SM). 


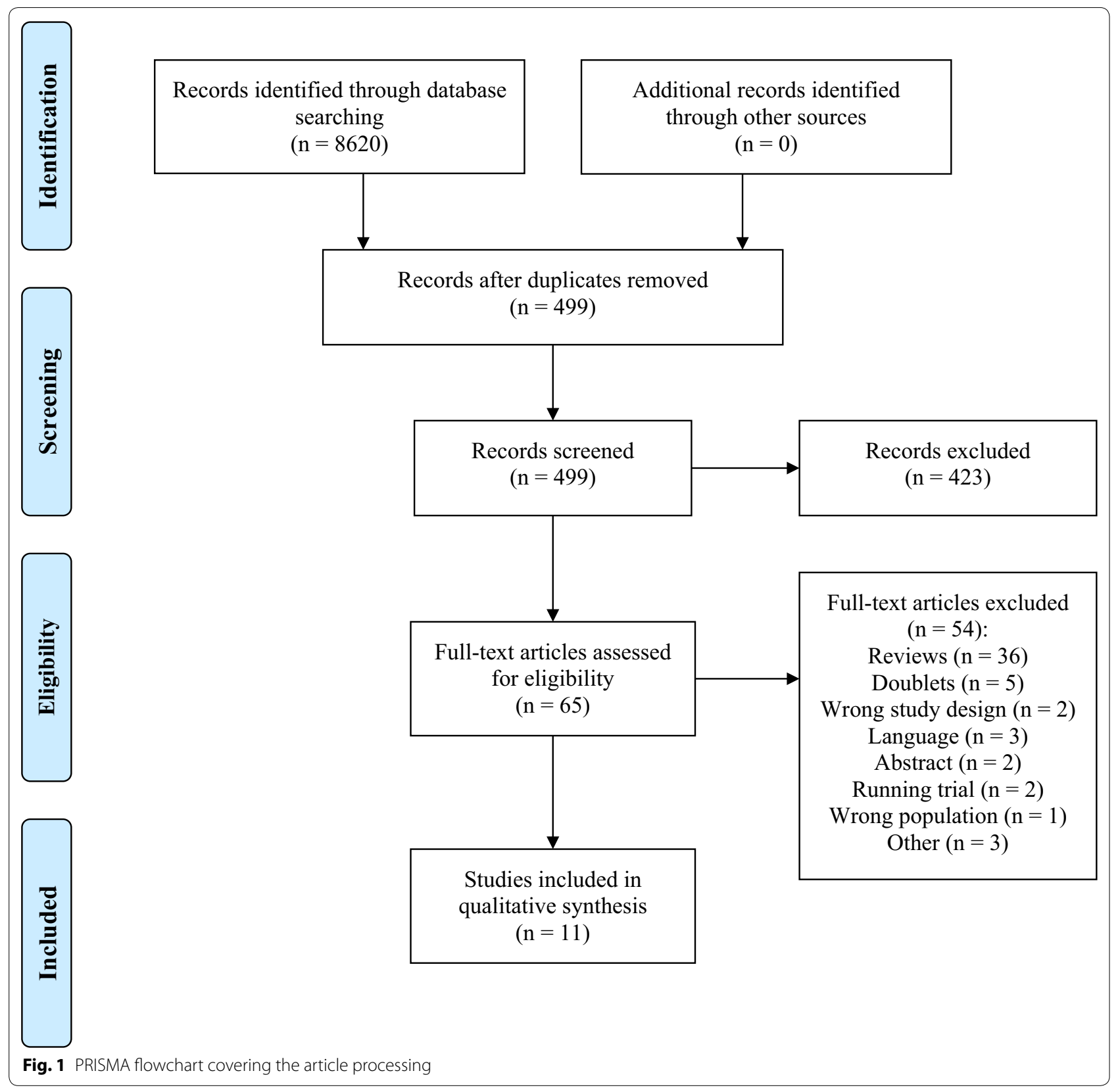

\section{Results}

\section{Identification of Studies}

The literature searches identified 620 studies to be screened. After removal of duplicates, 499 studies were screened by abstract. A total of 65 studies that investigated the use of ketamine in humans were screened by reading the full text. Eleven studies were eligible for inclusion, containing a total of 334 patients. The reference lists in the included studies were manually screened but did not contribute with any further studies. A frequent cause of exclusion was the use of ketamine on a non-comparable study population (e.g., elective surgery patients, abdominal surgery patients, or patients undergoing cardiac surgery). One study by Carlson et al. [14] was excluded since the study is an evaluation of an already included study by Hertle et al. [9].

\section{Quality of Included Studies}

All included studies were evaluated by design. Overall, the studies showed a large variation in quality, and we found a large degree of heterogeneity in methods and design. One small blinded randomized controlled trial 
with low risk of selection bias, performance bias, detection bias, and attrition bias was found [15]. However, in that particular study, the risk of reporting bias was unclear. Most of the remaining included studies were prospective studies without randomization and blinding, resulting in a high risk of selection bias, performance bias, and assessment bias [16-20]. Three studies [21-23] used randomized controlled designs but did not have a proper allocation concealment and no blinding, resulting in high risk of bias. Two studies $[9,24]$ were performed retrospectively with no possibility of randomization and blinding. For further information, see Table 1.

\section{Main Results}

\section{Human Cerebral Circulation: Intracranial Pressure}

Relevant study characteristics from the included studies are presented in Table 2 .

Of the 11 included studies, seven evaluated the effect on intracranial pressure (ICP) [15-17, 19-22]. All seven studies were conducted in adult $[15,16,19-22]$ or pediatric [17] patients with TBI, subarachnoid hemorrhage $(\mathrm{SAH})$, or other intracranial illnesses (e.g., drowned patients with cerebral edema) in an ICU setting and under controlled ventilation. Three studies found no overall difference in ICP between patients receiving ketamine and the matching control group $[15,21,22]$. One study reported slightly elevated ICP of 5 and $8 \mathrm{mmHg}$ in day 8 and 10 with an overall median of $14.6 \mathrm{mmHg}$ [19]. One study found an elevated ICP during tracheal suctioning of head injured patients [20]. The ICP was elevated $4.1 \mathrm{mmHg}$ and $7.5 \mathrm{mmHg}$ in the intervention and control, respectively. Furthermore, it was found that ketamine in this study prevented cough reflexes [20]. One study reported both decreased ICP values (range 1-5 $\mathrm{mmHg}$ ) $2 \mathrm{~min}$ after ketamine administration and elevated (range $3-4 \mathrm{mmHg}$ ) ICP values $30 \mathrm{~min}$ after ketamine bolus. However, no evidence of harm was reported despite the ICP elevation [16]. One study found decreased ICP values from $25.8 \pm 8.4$ to $18.0 \pm 8.5 \mathrm{mmHg}$ [17] for 2 min following ketamine administration in a pediatric population. In this study, 20 of the 30 included patients received hyperosmolar therapy (either mannitol or $3 \% \mathrm{NaCl}$ ) shortly before ketamine administration [17]. Overall, none of the seven studies reported persistent adverse effects in relation to increased ICP or increased mortality after ketamine administration in brain-injured patients [15, 16, 19-22].

\section{Human Cerebral Circulation: Cerebral Perfusion Pressure} Seven [15-17, 19-22] studies included monitoring of the cerebral perfusion pressure (CPP). Only one [17] of the seven studies found increased CPP values following ketamine administration. The CPP increased by $3.9 \mathrm{mmHg}$ 2 min after ketamine administration [17].

\section{Human Cerebral Circulation: MAP and HR}

Eight studies [15-17, 19-22, 24] evaluated human cerebral circulation. However, six did not report or did not find any difference in MAP and HR $[15,16,20-22$, 24]. One study found significantly elevated MAP in one

Table 1 Risk of bias assessment using the Cochrane risk of bias tool

\begin{tabular}{|c|c|c|c|c|c|c|}
\hline \multirow[t]{2}{*}{ Study } & \multicolumn{6}{|c|}{ The Cochrane risk of bias tool } \\
\hline & $\begin{array}{l}\text { Random sequence } \\
\text { generation (selection } \\
\text { bias) }\end{array}$ & $\begin{array}{l}\text { Allocation } \\
\text { concealment (selection } \\
\text { bias) }\end{array}$ & $\begin{array}{l}\text { Blinding of participants } \\
\text { (performance bias) }\end{array}$ & $\begin{array}{l}\text { Blinding of outcome } \\
\text { assessment (detection } \\
\text { bias) }\end{array}$ & $\begin{array}{l}\text { Incomplete outcome } \\
\text { data (attrition bias) }\end{array}$ & $\begin{array}{l}\text { Selective reporting } \\
\text { (reporting bias) }\end{array}$ \\
\hline $\begin{array}{l}\text { Gratwohl } \\
\text { et al. [24] }\end{array}$ & $\bullet$ & $\bullet$ & $\bullet$ & $\bullet$ & - & - \\
\hline $\begin{array}{l}\text { Albanése } \\
\text { et al. [16] }\end{array}$ & $\bullet$ & $\bullet$ & $\bullet$ & $\bullet$ & - & - \\
\hline $\begin{array}{l}\text { Bourgoin } \\
\text { et al. [21] }\end{array}$ & - & $\bullet$ & $\bullet$ & - & - & - \\
\hline $\begin{array}{l}\text { Bourgoin } \\
\text { et al. [15] }\end{array}$ & - & $\bullet$ & - & - & - & - \\
\hline $\begin{array}{l}\text { Bar- } \\
\text { Joseph et } \\
\text { al. [17] }\end{array}$ & $\bullet$ & $\bullet$ & $\bullet$ & $\bullet$ & - & $\bullet$ \\
\hline $\begin{array}{l}\text { Hertle et } \\
\text { al. [9] }\end{array}$ & $\bullet$ & $\bullet$ & - & $\bullet$ & $\bullet$ & - \\
\hline $\begin{array}{l}\text { Hertle et } \\
\text { al. [18] }\end{array}$ & $\bullet$ & $\bullet$ & $\bullet$ & $\bullet$ & $\bullet$ & - \\
\hline $\begin{array}{l}\text { Schmittner } \\
\text { et al. [22] }\end{array}$ & - & - & - & - & $\bullet$ & - \\
\hline $\begin{array}{l}\text { Caricato et } \\
\text { al. [20] }\end{array}$ & $\bullet$ & $\bullet$ & $\bullet$ & - & - & - \\
\hline $\begin{array}{l}\text { Carlson et } \\
\text { al. (2018) }\end{array}$ & - & $\bullet$ & $\bullet$ & - & - & - \\
\hline
\end{tabular}




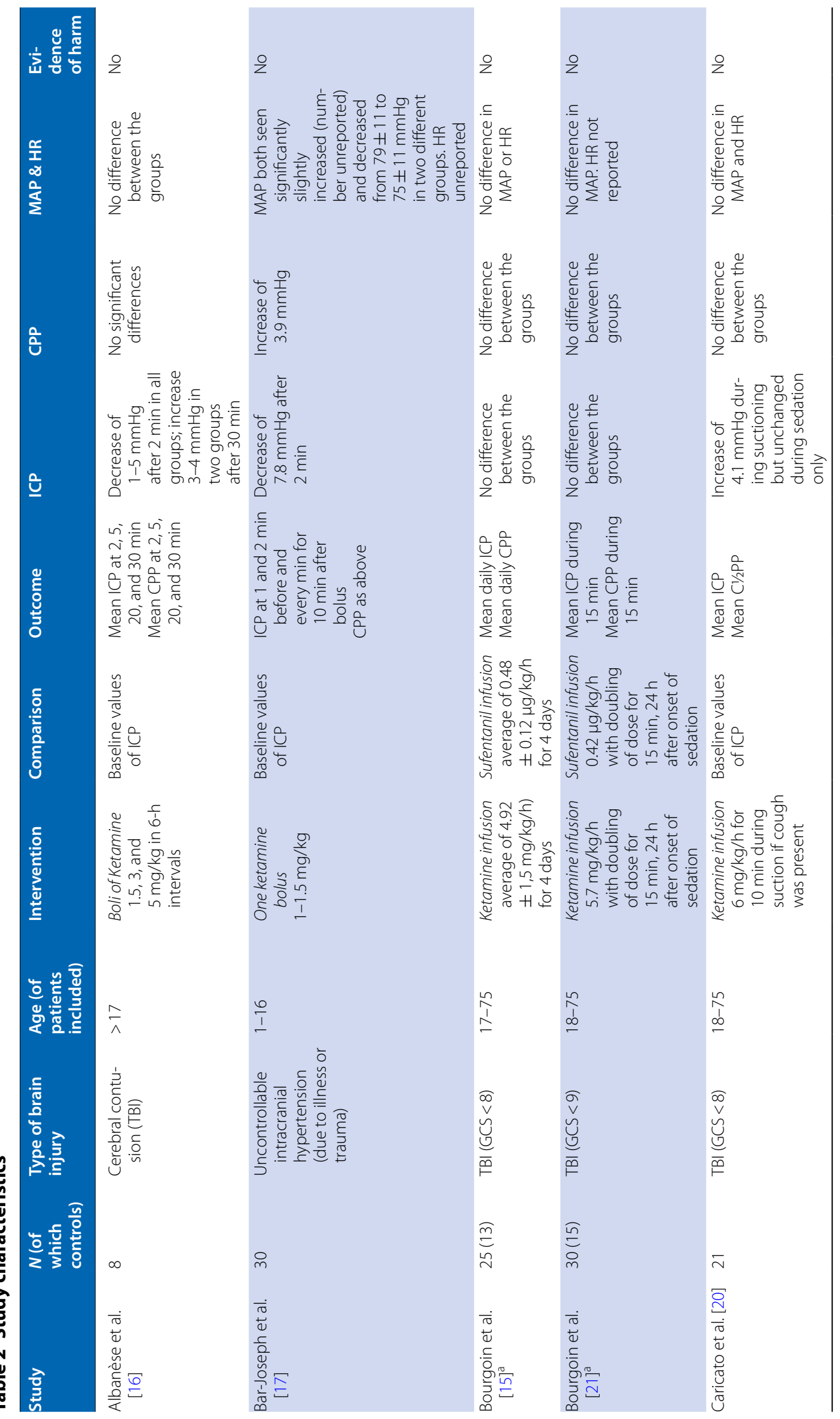




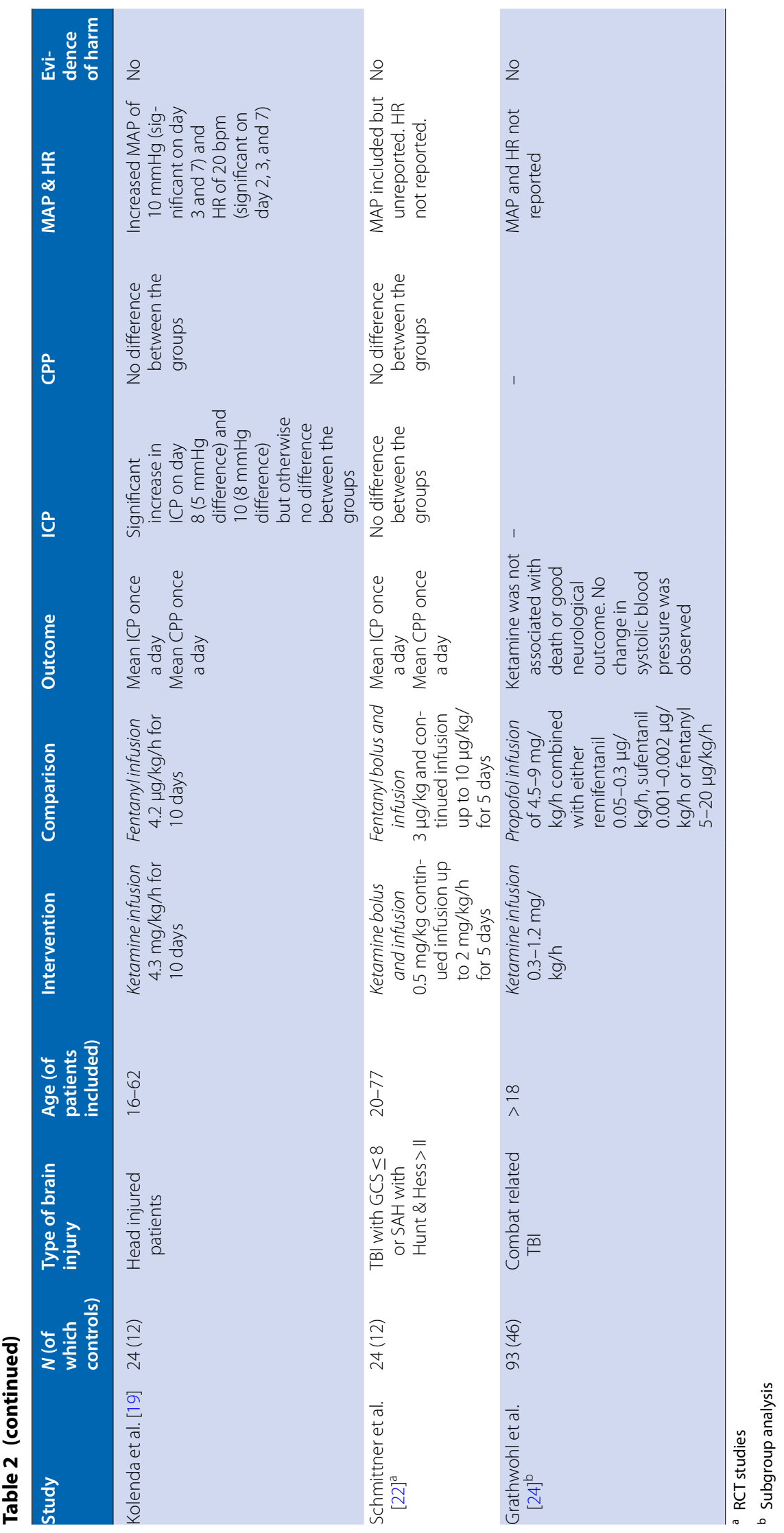


group as a response to ketamine administration prior to a potentially distressing intervention, but the actual number was not reported [17]. In the same study, a decreased MAP of $5 \pm 11 \mathrm{mmHg}$ was seen when ketamine was administered with the purpose of lowering ICP [17]. However, HR was unreported. One last study saw increased MAP of $10 \mathrm{mmHg}$ on day 3 and 7 and elevated HR with $20 \mathrm{bpm}$ on day 2, 3, and 7 [19].

\section{Spreading Depolarizations and Burst Suppressions During Ketamine Treatment}

Four studies [9, 16, 18, 23] investigated spreading depolarizations (SD) and burst suppressions [electroencephalographic (EEG) activity] during ketamine administrations in brain-injured patients. Relevant study characteristics are presented in Table 3.

Two studies evaluated SDs in patients who were treated with ketamine following acute brain injury [9, 18]. Both studies were from the same research group. In one of the two studies, ketamine was found to significantly decrease SD with a dose-response relationship [9].

The other study, a retrospective multicenter study [18], investigated electrocorticographic (ECoG) alpha, beta, delta, and theta frequencies. Alpha, beta, delta, and theta frequencies are direct recordings of electrical potentials associated with brain activity. It was found that in 43 patients, the occurrence of alpha, beta, delta, and theta frequencies, and their mutual proportion was a potential predictor of the occurrence of SD. Firstly, the investigators found that when the occurrence of beta frequencies diminished, an increased number of SDs took place, indicating an association between beta frequencies and SD [18]. Secondly, an increased occurrence of beta frequencies and thus a reduced occurrence of SD were observed, accordingly indicating that ketamine increases the occurrence of beta frequencies and therefore limits SD [18]. With regard to the three remaining electrocorticographic frequencies alpha, delta, and theta, no association was found in relation to the occurrence of SD [18]. This is supported by a third study [16] which found a dose-related burst suppression (a low amplitude fast activity with electrogenic depression) on EEG of patients treated with ketamine. However, these EEG recordings were performed externally as usual, with electrodes on the scalp in contrast to the invasive SD recordings. A fourth small randomized study [23] also demonstrated an inhibitory dose-dependent effect of ketamine on the occurrence of SD with an odds ratio of 13.84 (95\% CI 1.99-1000), for the occurrence of SD when not treated with ketamine or when treated with a dose less than $1.15 \mathrm{mg} / \mathrm{kg} / \mathrm{h}$.

\section{Ketamine Dosage}

The ketamine dosage applied varied between study groups. The dose used in bolus-only studies ranged from 1 to $5 \mathrm{mg} / \mathrm{kg}$ ketamine $[16,17,22]$. In the remaining studies, ketamine was administered by infusion with an infusion rate that varied from 0.3 to $200 \mathrm{mg} / \mathrm{kg} / \mathrm{h}[9$,

Table 3 Study characteristics

\begin{tabular}{|c|c|c|c|c|c|c|c|c|}
\hline Study & $\mathbf{N}$ & Patients & Age & Intervention & Comparison & Outcome & SD & $\begin{array}{l}\text { Evi- } \\
\text { dence } \\
\text { of harm }\end{array}$ \\
\hline Hertle et al. [9] & 26 & $\begin{array}{l}\text { Brain injury requir- } \\
\text { ing craniotomy }\end{array}$ & $18-79$ & $\begin{array}{l}\text { Ketamine infusion } \\
200 \mathrm{mg} \text { (median)/h } \\
\text { during } 2168 \mathrm{~h} \text { of } \\
\text { ECG recordings }\end{array}$ & $\begin{array}{l}\text { Baseline ECG prior } \\
\text { to ketamine } \\
\text { administration }\end{array}$ & $\begin{array}{l}\text { Number of SD } \\
\text { Number of SD } \\
\text { clusters }\end{array}$ & $\begin{array}{l}\text { Odds ratio for } \\
\text { SD occurrence } \\
\text { reduced to } 0.38 \\
\text { when receiving } \\
\text { ketamine } \\
\text { Odds ratio for SD } \\
\text { cluster occur- } \\
\text { rence reduced to } \\
0.2 \text { when receiv- } \\
\text { ing ketamine }\end{array}$ & No \\
\hline Hertle et al. [18] & 43 & $\begin{array}{l}\text { Brain injury requir- } \\
\text { ing craniotomy }\end{array}$ & $>50$ & $\begin{array}{l}\text { Ketamine infusion } \\
(5-250 \mathrm{mg} / \mathrm{h})\end{array}$ & $\begin{array}{l}\text { Baseline ECG prior } \\
\text { to ketamine } \\
\text { administration }\end{array}$ & $\begin{array}{l}\text { Number of SD } \\
\text { Beta frequency } \\
\text { activity }\end{array}$ & $\begin{array}{l}\text { Reduced number } \\
\text { of SD } \\
\text { Increased beta fre- } \\
\text { quency activity }\end{array}$ & No \\
\hline Carlson et al. [23] & 10 & $\mathrm{TBI}$ and $\mathrm{SAH}$ & $>45$ & $\begin{array}{l}\text { Ketamine infusion } \\
0.1 \mathrm{mg} / \mathrm{kg} / \mathrm{h} \text { as } \\
\text { basal infusion, } \\
\text { titrated after Riker } \\
\text { sedation-agita- } \\
\text { tion scale score } \\
\text { of } 4\end{array}$ & $\begin{array}{l}\text { Baseline ECG prior } \\
\text { to ketamine } \\
\text { administration }\end{array}$ & Number of SD & $\begin{array}{l}\text { Reduced number } \\
\text { of SD }\end{array}$ & No \\
\hline
\end{tabular}


$15,18-24]$. Only four studies [15, 20-22] reported arguments for why the exact ketamine dose was chosen. Typically, the administration was titrated according to the level of sedation, e.g., the Ramsay score or the Riker sedation-agitation scale.

No authors reported potentially fatal or fatal side effects relating to the use of ketamine.

\section{Discussion}

The interest in ketamine has lasted over 50 years, and ketamine has been used for several purposes. Judging by the number of studies, the interest in ketamine as an alternative anesthetic and sedation agent has been constant; only interrupted by a 5-year period in the $1990 \mathrm{~s}$ where data from the 1970 received renewed interest leading to the conception that ketamine was the main reason for elevated ICP in patients with TBI. In this review, we included 11 studies with a total of 334 patients. Overall, we found no evidence indicating that the use of ketamine in patients with acute brain injury results in worsened cerebral conditions. Specifically, no negative effects were found in ICP, CPP, the occurrence of additional SDs, altered hemodynamics, or mortality. Furthermore, no studies reported any adverse events. These effects, however, cannot be ruled out although no apparent sentinel events were reported.

The overall quality of evidence was low in randomized controlled trials (with only two studies addressing selection bias, performance bias, detection bias, and attrition bias) and very low for observational and retrospective studies.

\section{Cerebral Circulation}

Ketamine is well known for its ability to stabilize and even stimulate the circulatory system compared to most intravenous anesthetics [3]. Its use in treatment of patients suffering from TBI or other conditions with the risk of elevated ICP have been debated since the 1960s after several studies found that ketamine contributed to an elevation in ICP [25]. In this systematic review, only two prospective studies $[19,20]$ showed elevated ICP during ketamine use. In one study, this elevation was observed during suctioning that is known to induce a raise in ICP, even among healthy volunteers [20]. The other study found elevated ICP in the ketamine group on two different days $(5 \mathrm{mmHg}$ and $8 \mathrm{mmHg}$ on day 8 and 10 , respectively) with an overall median ICP of $14.6 \mathrm{mmHg}$ [19]. However, this minor elevation of ICP, still within the normal range, does not seem clinically relevant. None of the three randomized controlled trials in adults $[15,21,22]$ found increased ICP levels during intravenous infusion of ketamine, nor was any effect on CPP or MAP reported. None of the prospective clinical controlled studies in adults found any change in MAP or CPP during ketamine administration. One randomized controlled trial involving children found a small increase in CPP [17]. Two studies in adults and children [16, 17] found decreased ICP values during ketamine administration. Both used a single bolus of ketamine and observed a decreased ICP shortly after administration.

\section{Human Cerebral Circulation: MAP and HR}

In one study, it was reported that MAP was elevated with $10 \mathrm{mmHg}$ in the ketamine group and the HR was elevated with $20 \mathrm{bpm}$ on day 2, 3, and 7 [19]. The same group saw more stable vital parameters and used less catecholamines in the ketamine group. One other study found both increased and decreased MAP values but did not report HR in the article [17]. Most of the studies used concomitant drugs, e.g., fentanyl, midazolam, or propofol which are known to cause hypotension and mask the sympathetic response of ketamine.

\section{Spreading Depolarizations During Ketamine Treatment}

Four studies $[9,16,18,23]$ included analysis of SDs on ECG recordings. Three studies $[9,16,23]$ showed a significant reduction in the occurrence of SD with a ketamine dose-related correlation. Increased SD was associated with poorer neurological outcome [9]. This indicates that ketamine might act as a neuroprotective agent through modulation of SD in the traumatic brain. One study [18] investigated whether spreading depolarizations could be predicted through electrocorticographic frequencies in patients suffering TBI. This study revealed frequent SDs in relation to suppressions of ECoG beta frequencies indicating that this could predict the occurrence of SD. Further, ketamine was found partially to increase the amount of beta frequencies and thereby inhibit the occurrence of SD [18]. However, this was a retrospective study with only a partial effect of ketamine on beta frequencies and SD, indicating that further prospective studies are warranted. Even externally EEG recordings showed burst suppression following ketamine administration supporting the theory of an inhibitory effect on neuronal activity of ketamine [16].

\section{Controlled Ventilation and Arterial $\mathrm{CO}_{2}$}

For several years, it has been recognized that controlled ventilation plays an important role in the management of patients with severe TBI [26]. However, one randomized controlled trial and two prospective trials on the effects of ketamine on neurological outcome did not report the targeted partial pressure of $\mathrm{CO}_{2}$ in arterial gasses of the patients included in the studies [17, 19, 22]. Furthermore, none of the eleven studies reported how often the partial pressure of $\mathrm{CO}_{2}$ was controlled. Two $[17,19]$ of the three 
studies $[17,19,22]$ that did not control $\mathrm{PaCO}_{2}$ found either lowered or elevated ICP levels. All studies used ventilators. No patients were on spontaneous breathing which, in an animal model, has shown to increase intracranial pressure during ketamine sedation [27]. We thus recommend hesitation in relation to conclusions regarding potential correlations between ketamine administration and changes in ICP levels. Non-standardized mechanical ventilation without control of arterial blood gases most probably may contribute to bias and confounding.

\section{Ketamine Dosage and Timing}

The general ketamine dosage varied greatly between the studies. Several studies used concomitant medication (propofol, fentanyl, sufentanil, midazolam, morphine, and etomidate), which might mask the true effect of ketamine. Propofol is widely used as supplemental medication and has been found to lower ICP briefly in patients with brain injury [28].

Furthermore, timing of administration of ketamine appears to be a turning point in animal studies and several treatment regimens have been investigated; administration before experimental TBI, administration simultaneously with TBI, and delayed administration of ketamine [29].

\section{Ketamine and Children}

Only one study investigating the effect of ketamine in children was identified [17]. In this study, the authors showed decreased ICP values and increased CPP shortly after ketamine administration [17].

However, as in many of the other available studies, no information with respect to mechanical ventilator settings or arterial blood gases was provided. Furthermore, two thirds of the patients received hyperosmolar fluid therapy shortly before ketamine administration thus making it difficult to assess the true effect of ketamine [17]. Many attempts have been made in order to elucidate whether anesthetic agents in general affect the developing human brain. Recently, a systemic review [30] investigating the effect of general anesthesia on children has been published. Children exposed to general anesthesia were investigated with respect to various parameters including cognition, sensory-motor development, academic achievement, and neuropsychological diagnoses in later life. Also, magnetic resonance imaging, serum biomarkers, mortality, neurological examination, measurement of head circumference, and impairment of vision were investigated. The studies concerned anesthesia in general, but no specific consideration was made regarding the kind of anesthetic agents utilized. To our knowledge, no studies, neither prospective nor retrospective, have been made on long-term outcome for children treated with ketamine as an anesthetic agent.

Based on the available data in pediatric patients, administration of ketamine to children should be approached with caution as limited data are present.

\section{Quality of Studies}

The overall quality of the included studies varies. Only one study [15] was assessed as having low risk of selection bias, performance bias, detection bias, and attrition bias with unclear risk of reporting bias using the Cochrane risk of bias tool. The general problem in this field is the lack of strong randomized controlled studies. We identified only three minor randomized controlled studies.

To summarize, we conclude that despite over 50 years of research in the field, the amount and quality of data supporting recommendation of the use of ketamine or not in patients with acute brain injury is not impressive. Numerous retrospective and prospective studies have been conducted, but all studies have weaknesses that render a solid recommendation impossible. However, none of the included studies showed any evidence of harm using ketamine to patients suffering from acute brain injury. The feasible and obvious next step would be to design a large controlled randomized double-blinded multicenter study investigating the use of ketamine in patients with acute brain injury addressing multiple confounders.

\section{Author details \\ ${ }^{1}$ The Mobile Emergency Care Unit, Department of Anaesthesiology and Inten- sive Care, Odense University Hospital, Odense, Denmark. ${ }^{2}$ The Prehospital Research Unit, Region of Southern Denmark, Odense University Hospital, Odense, Denmark. ${ }^{3}$ Department of Regional Health Research, University of Southern Denmark, Odense, Denmark. ${ }^{4}$ Department of Clinical Research, University of Southern Denmark, Odense, Denmark. ${ }^{5}$ Department of Anaes- thesiology and Intensive Care, Kolding Hospital, 6000 Kolding, Denmark.}

\section{Author Contributions}

$\mathrm{KL}, \mathrm{ACB}$, and SM conceived the idea. MCTG and $\mathrm{ACB}$ reviewed the initial titles. MCTG and ACB reviewed abstracts and full articles, extracted data and performed the bias assessment. All authors contributed substantially to the design of the review, interpreted the results, critically revised the manuscript, and approved the manuscript prior to submission.

\section{Source of Support}

No funding was received.

Conflict of interest

The authors declare that they have no conflict of interest.

\section{Open Access}

This article is licensed under a Creative Commons Attribution 4.0 International License, which permits use, sharing, adaptation, distribution and reproduction in any medium or format, as long as you give appropriate credit to the original author(s) and the source, provide a link to the Creative Commons licence, and indicate if changes were made. The images or other third party material in this article are included in the article's Creative Commons licence, unless indicated otherwise in a credit line to the material. If material is not included in the 
article's Creative Commons licence and your intended use is not permitted by statutory regulation or exceeds the permitted use, you will need to obtain permission directly from the copyright holder. To view a copy of this licence, visit http://creativecommons.org/licenses/by/4.0/.

\section{Publisher's Note}

Springer Nature remains neutral with regard to jurisdictional claims in published maps and institutional affiliations.

Published online: 23 April 2020

\section{References}

1. Domino EF. Taming the ketamine tiger. Anesthesiology. 2010;113(3):678-84

2. Zanos P, Moaddel R, Morris PJ, et al. Ketamine and ketamine metabolite pharmacology: insights into therapeutic mechanisms. Pharmacol Rev. 2018;70(3):621-60.

3. Aroni F, lacovidou N, Dontas I, Pourzitaki C, Xanthos T. Pharmacological aspects and potential new clinical applications of ketamine: reevaluation of an old drug. J Clin Pharmacol. 2009;49(8):957-64.

4. Takeshita H, Okuda Y, Sari A. The effects of ketamine on cerebral circulation and metabolism in man. Anesthesiology. 1972;36(1):69-75.

5. Hansen AJ, Zeuthen T. Extracellular ion concentrations during spreading depression and ischemia in the rat brain cortex. Acta Physiol Scand. 1981;113(4):437-45.

6. Dreier JP, Fabricius M, Ayata C, et al. Recording, analysis, and interpretation of spreading depolarizations in neurointensive care: review and recommendations of the COSBID research group. J Cereb Blood Flow Metab. 2017;37(5):1595-625.

7. Kramer DR, Fujii T, Ohiorhenuan I, Liu CY. Cortical spreading depolarization: pathophysiology, implications, and future directions. J Clin Neurosci. 2016;24:22-7.

8. Stevens R, Koehler R. Pathophysiological insights into spreading depolarization in severe traumatic brain injury. Neurocrit Care. 2019;30(3):569-71.

9. Hertle DN, Dreier JP, Woitzik J, et al. Effect of analgesics and sedatives on the occurrence of spreading depolarizations accompanying acute brain injury. Brain. 2012;135(8):2390-8.

10. Moher D, Liberati A, Tetzlaff J, Altman DG. Preferred reporting items for systematic reviews and meta-analyses: the PRISMA statement. J Clin Epidemiol. 2009;62(10):1006-12.

11. Covidence homepage. Available from: https://www.covidence.org/home. Accessed 17 Apr 2019.

12. Counsell C. Formulating questions and locating primary studies for inclusion in systematic reviews. Ann Intern Med. 1997;127(5):380-7.

13. Higgins JP, Green S. Cochrane handbook for systematic reviews of interventions: Cochrane book series. New York: Wiley; 2008. ISBN 978-0-470-51845-8.

14. Carlson AP, Shuttleworth CW. Decreased cortical spreading depolarizations in neurosurgical patients being given ketamine. Fut Neurol. 2013:8(1):17-20.
15. Bourgoin A, Albanèse J, Wereszczynski N, Charbit M, Vialet R, Martin C Safety of sedation with ketamine in severe head injury patients: comparison with sufentanil. Crit Care Med. 2003;31(3):711-7.

16. Albanèse J, Arnaud S, Rey M, Thomachot L, Alliez B, Martin C. Ketamine decreases intracranial pressure and electroencephalographic activity in traumatic brain injury patients during propofol sedation. Anesthesiology. 1997;87(6):1328-34

17. Bar-Joseph G, Guilburd Y, Tamir A, Guilburd JN. Effectiveness of ketamine in decreasing intracranial pressure in children with intracranial hypertension: clinical article. J Neurosurg Pediatr. 2009;4(1):40-6.

18. Hertle DN, Heer M, Santos E, et al. Changes in electrocorticographic beta frequency components precede spreading depolarization in patients with acute brain injury. Clin Neurophysiol. 2016;127(7):2661-7.

19. Kolenda H, Gremmelt A, Rading S, Braun U, Markakis E. Ketamine for analgosedative therapy in intensive care treatment of head-injured patients. Acta Neurochir (Wien). 1996;138(10):1193-9.

20. Caricato A, Tersali A, Pitoni S, et al. Racemic ketamine in adult head injury patients: use in endotracheal suctioning. Crit Care. 2013;17(6):R267.

21. Bourgoin A, Albanèse J, Léone M, Sampol-Manos E, Viviand X, Martin C. Effects of sufentanil or ketamine administered in target-controlled infusion on the cerebral hemodynamics of severely brain-injured patients. Crit Care Med. 2005;33(5):1109-13.

22. Schmittner MD, Vajkoczy SL, Horn P, et al. Effects of fentanyl and S(+)ketamine on cerebral hemodynamics, gastrointestinal motility, and need of vasopressors in patients with intracranial pathologies: a pilot study. J Neurosurg Anesthesiol. 2007;19(4):257-62.

23. Carlson AP, Abbas M, Alunday RL, Qeadan F, Shuttleworth CW. Spreading depolarization in acute brain injury inhibited by ketamine: a prospective, randomized, multiple crossover trial. J Neurosurg. 2019;130(5):1513-9.

24. Grathwohl KW, Black IH, Spinella PC, et al. Total intravenous anesthesia including ketamine versus volatile gas anesthesia for combat-related operative traumatic brain injury. Anesthesiology. 2008;109(1):44-53.

25. Green SM, Andolfatto G, Krauss BS. Ketamine and intracranial pressure: no contraindication except hydrocephalus. Ann Emerg Med. 2015;65(1):52-4.

26. Freeman WD. Management of intracranial pressure. Neurocrit Care. 2015;21(5):1299-323

27. Pfenninger E, Grünert A, Bowdler I, Kilian J. The effect of ketamine on intracranial pressure during haemorrhagic shock under the conditions of both spontaneous breathing and controlled ventilation. Acta Neurochir (Wien). 1985;78(3-4):113-8.

28. Colton $\mathrm{K}$, Yang S, Hu PF, et al. Intracranial pressure response after pharmacologic treatment of intracranial hypertension. J Trauma Acute Care Surg. 2014;77(1):47-53.

29. Statler KD, Alexander $H$, Vagni $V$, et al. Comparison of seven anesthetic agents on outcome after experimental traumatic brain injury in adult, male rats. J Neurotrauma. 2006;23(1):97-108.

30. Clausen NG, Kähler S, Hansen TG. Systematic review of the neurocognitive outcomes used in studies of paediatric anaesthesia neurotoxicity. $\mathrm{Br}$ J Anaesth. 2018;120(6):1255-73. 